\title{
Investigasi sifat mekanis sambungan Dissimilar Friction Stir welding (DFSW) Aluminium Alloys (AA5052 to AA6061)
}

\author{
Muhammad Arsyad Suyuti ${ }^{1}$, Apollo1), Muhammad Iswar ${ }^{1}$, Rusdi Nur $\left.{ }^{1,2}\right)^{*}$ \\ 1)Jurusan Teknik Mesin Politeknik Negeri Ujung Pandang, Tamalanrea Makassar Sulawesi Selatan Indonesia \\ 2)Center for Materials and Manufacturing Politeknik Negeri Ujung Pandang \\ Tamalanrea, Makassar, Sulawesi Selatan Indonesia
}

Naskah diterima 27/07/2020; direvisi 06/11/2020; disetujui 14/11/2020

doi: https://doi.org/10.24843/JEM.2020.v13.i02.p01

\begin{abstract}
Abstrak
Penyambungan antara dua material yang berbeda (AA5052 dan AA6061) dapat dilakukan dengan proses Dissimilar Friction Stir Welding (DFSW). oleh karena itu, penelitian ini dilakukan untuk menganalisa sifat mekanis sambungan hasil pengelasan dissimilar. Pada penelitian ini proses DFSW menggunakan tool dengan shoulder $\varnothing 17,8 \mathrm{~mm}$ dan pin berbentuk silinder $\varnothing 5$ $\mathrm{mm}$. Penyambugan FSW dikerjakan pada mesin frais konvensional dengan variasi putaran tool $1300 \mathrm{rpm}, 1950 \mathrm{rpm}$ dan 2850 $\mathrm{rpm}$, sedangkan variasi kecepatan pengelasan (feeding) $43 \mathrm{~mm} / \mathrm{min}, 130 \mathrm{~mm} / \mathrm{min}$ dan $240 \mathrm{~mm} / \mathrm{min}$. Hasil pengujian sifat mekanis menunjukkan nilai kekerasan tertinggi yang diperoleh sebesar 55,3 HBN pada putaran $1300 \mathrm{rpm}$ dengan feeding 240 $\mathrm{mm} / \mathrm{min}$, kdapatekuatan tarik tertinggi terjadi untuk putaran $1300 \mathrm{rpm}$ dan feeding $240 \mathrm{~mm} / \mathrm{min}$ sebesar $123,51 \mathrm{MPa}$. Patahan hasil uji tarik umumnya terjadi pada daerah HAZ dan Nugget logam dasar AA5052. Hasil investigasi menunjukkan bahwa sambungan DFSW material alumunium paduan AA 6061 dan AA 5052 dapat tersambung dengan baik, namun dari segi kekuatan umumunya kekuatan tarik daerah sambungan (HAZ dan Nugget) lebih kecil dari kekuatan tarik logam dasar. Sambungan DFSW ini adapt diterapkan untuk sambungan yang tidak menerima beban atau kekuatan tarik akibat beban yang diterima sambungan tidak melebih besar dari kekuatan tarik maksimum logam dasar AA 5052
\end{abstract}

Kata kunci: Paduan alumunium, feeding, Friction Stir Welding (FSW), tool, nugget, sifat mekanis

\section{Abstract}

The joint for two different materials (AA5052 and AA6061) can be done by the Dissimilar Friction Stir Welding (DFSW) process. Therefore, this study was conducted to analyze the mechanical properties of dissimilar welding joints. In this study the DFSW process uses a tool with a shoulder $\varnothing 17.8 \mathrm{~mm}$ and a cylindrical pin $\varnothing 5 \mathrm{~mm}$. FSW blocking is done on conventional milling machines with $1300 \mathrm{rpm}, 1950 \mathrm{rpm}$ and $2850 \mathrm{rpm}$ tool rotation variations, while the welding speed variations are $43 \mathrm{~mm} / \mathrm{min}$, $130 \mathrm{~mm} / \mathrm{min}$ and $240 \mathrm{~mm} / \mathrm{min}$. The results of mechanical properties testing showed the highest hardness value obtained was $55.3 \mathrm{HBN}$ at $1300 \mathrm{rpm}$ with $240 \mathrm{~mm} / \mathrm{min}$ feeding, the highest tensile strength occurred for $1300 \mathrm{rpm}$ and $240 \mathrm{~mm} / \mathrm{min}$ feeding at $123.51 \mathrm{MPa}$. The fracture of the tensile test results generally occurs in the HAZ area and the AA5052 base metal Nugget. Investigation results show that the DFSW connection of aluminum alloy material AA 6061 and AA 5052 adapt is well connected, but in terms of general strength the tensile strength of the joint (HAZ and Nugget) is smaller than the tensile strength of the base metal. This DFSW connection adaptation is applied to connections that do not accept load or tensile strength due to the load received by the connection not to exceed the maximum tensile strength of base metal AA 5052

Keywords: Alumunium allloy, feeding, Friction Stir Welding (FSW), tool, nugget zone, mechanical properties

\section{Pendahuluan}

Aluminium paduan telah banyak digunakan dalam penerbangan, kedirgantaraan, pengiriman, dan transportasi industri karena keuntungan mereka dari kekuatan tinggi tertentu, tingkat kelelahan yang baik, kuat dan tahan korosi[1]. Namun, pengelasan aluminium paduan mempunyai tantangan besar. Metode pengelasan tradisional tidak cocok untuk paduan aluminium, khususnya paduan aluminium berbeda, karena mereka rentan untuk menghasilkan cacat seperti porositas dan retak selama pembekuan [2]. Aluminium 6061 paduan umumnya digunakan untuk pembangunan struktur pesawat, seperti sayap dan perlengkapan didalam pesawat baik pesawat komersial atau militer. Aluminium 6061 paduan umumnya hadir dengan sifat mampu las rendah menggunakan proses pengelasan tradisional [3]. AA5052 merupakan aluminium paduan Al-Mg, yang banyan digunakan pada industri otomotif secara luas karena mampu las dan ketahanan korosi yang sangat baik [4]. AA5052 adalah paduan solid state yang dapat diperkuat dengan dislokasi, dan penguatan batas-butir. AA6061 (aluminium alloy Al-Mg-Si) juga telah banyak digunakan untuk memproduksi komponen struktural otomotif karena kombinasi yang menarik dari kekuatan yang unggul dan biaya rendah [5].

Friction-Stir Welding (FSW), proses solid state, mencegah pembentukan struktur pemadatan dan oleh karena itu secara luas dianggap sebagai teknik menyambung sangat menjanjikan. Dalam paduan aluminium 6xxx, FSW juga menginduksi fenomena presipitasi atau pengendapan yang kompleks[6]. Pengelasan dengan logam dasar berbeda (dissimilar) memiliki manfaat bagi industri yang modern dimana sering ada keharusan untuk menghubungkan bagian yang berbeda dan komponen untuk mengurangi biaya atau untuk menggunakan bahan terbaik untuk menghasilkan produk bermutu [7]. Dissimilar Friction Stir Welding (DFSW) adalah aplikasi Friction Stir

*Korespondensi: Tel./Fax.: +6282190178974/-

E-mail: rusdinur@poliupg.ac.id 
Welding (FSW), diciptakan pada The Welding Institute (TWI) pada tahun 1991, untuk menyambung logam dasar yang berbeda termasuk aluminium, tembaga, baja, titanium, magnesium dan bahan lainnya. Hal ini didasarkan pada pengelasan solid state yang tidak mencair [8].

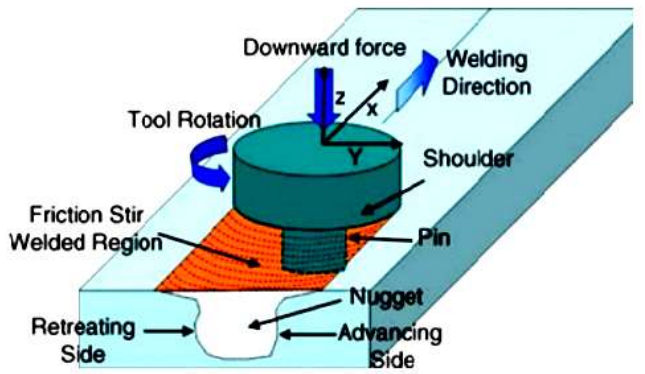

Gambar. 1. Skema dari Friction Stir Welding [9]

Terdapat beberapa parameter yang dipertimbangkan dalam pengelasan FSW diantaranya kecepatan putaran, kemiringan alat, feeding, geometri dan dimensi pin, geometri dan dimensi shoulder, material tool, dan lain-lain [10]. Friction Stir Welding (FSW) merupakan salah satu metode penyambungan pengelasan alternatif yang baru berkembang saat ini dengan kualitas sambungan pengelasan yang cukup baik. Proses ini mudah dilakukan dan ekonomis. Pengelasan dissimilar alminium paduan AA 5052 dan AA 6061 merupakan salah satu sambungan dissimilar FSW yang dapat diterapkan dalam industri manufaktur secara luas, sehingga perlu dilakukan kajian pengaruh parameter variasi putaran tool, feed rate, dan tool terhadap sifat mekanis sambungan.

\section{Metode Penelitian}

\subsection{Material dan Peralatan}

Penelitian ini dilaksanakan di bengkel Mekanik dan Laboratoium Mekanik Politeknik Negeri Ujung Pandang dengan menggunakan mesin frais dan Universal Testing Machine (UTM) merek Galdabini tipe PM 100 berkapasitas beban maksimum $100 \mathrm{KN}$.

Material logam dasar (base metal) yang digunakan dalam penyambungan dengan metode Dissimilar Friction Stir Welding (DFSW) adalah aluminiun paduan AA 5052 dan AA 6061 dengan ukuran 150 × 90 × 4 mm seperti ditunjukkan pada gambar 2. Sedangkan tool yang digunakan memiliki shoulder $\varnothing 17,8 \mathrm{~mm}$ dan pin berbentuk selinder $\varnothing 5$ $\mathrm{mm}$ seperti terlihat pada gambar 3 .

Tabel 1. Kandungan komposisi kimia aluminium paduan AA 5052 dan AA 6061

\begin{tabular}{|c|c|c|}
\hline Elemen & AA5052 & AA6061 \\
\hline $\mathrm{Si}$ & 0,35 & 0,64 \\
\hline $\mathrm{Fe}$ & 0,40 & 0,20 \\
\hline $\mathrm{Cu}$ & 0,10 & 0,19 \\
\hline $\mathrm{Mn}$ & 0,10 & 0,06 \\
\hline $\mathrm{Mg}$ & $2,2-2,8$ & 1,00 \\
\hline $\mathrm{Cr}$ & $0,15-0,35$ & 0,15 \\
\hline $\mathrm{Zn}$ & 0,10 & 0,05 \\
\hline $\mathrm{Ti}$ & - & 0,07 \\
\hline
\end{tabular}

Material logam dasar (base metal) yang digunakan dalam pengelasan DFSW adalah aluminium paduan jenis AA 5052 dan AA 6061 dengan kandungan komposisi kimia berdasarkan sertifikat pabrik tercantum pada Tabel 1.

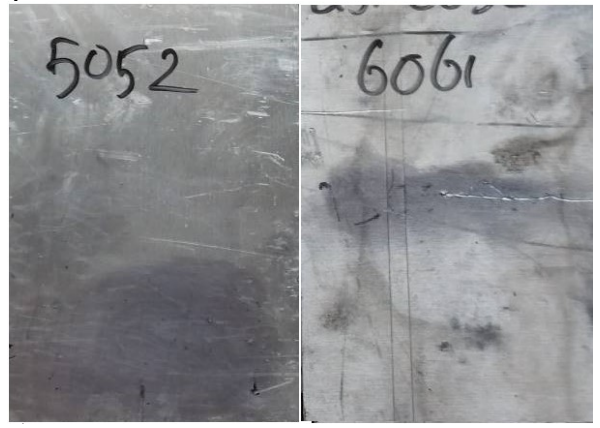

Gambar 2. Logam dasar yang akan diuji

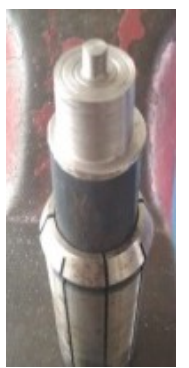

Gambar 3. Tool yang digunakan dalam FSW

Pengelasan DFSW material aluminium paduan AA 5052 to AA 6061 dikerjakan menggunakan mesin frais merek MINYANG dengan cara memasang benda kerja pada meja mesin sedangkan tool shoulder dipasang pada tool mesin frais tersebut. Adapun proses pengelasan dan sambungan hasil pengelasan DFSW dapat dilihat pada gambar 4 dan 5 .
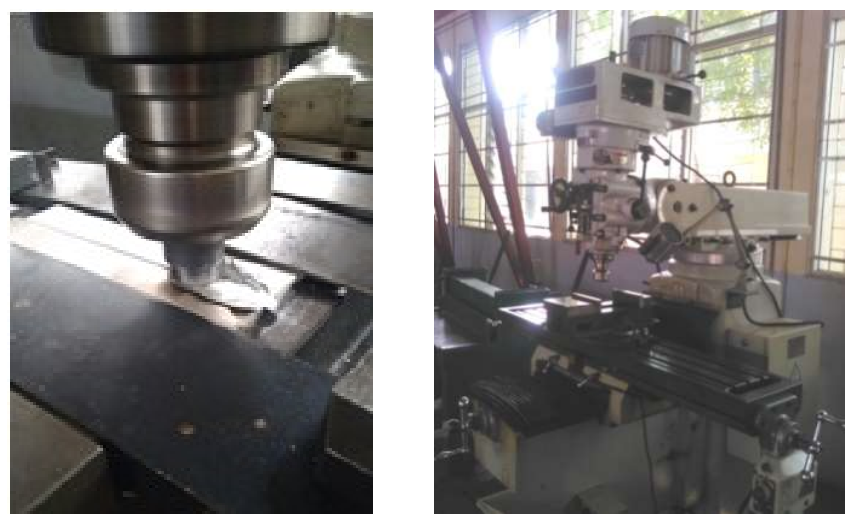

Gambar 4. Proses pengelasan Dissimilar FSW

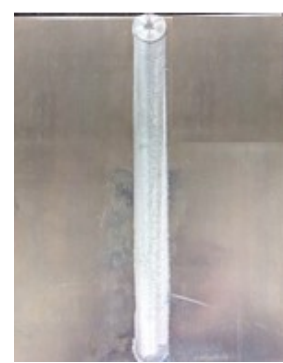

Gambar 5. Hasil pengelasan Dissimilar FSW 


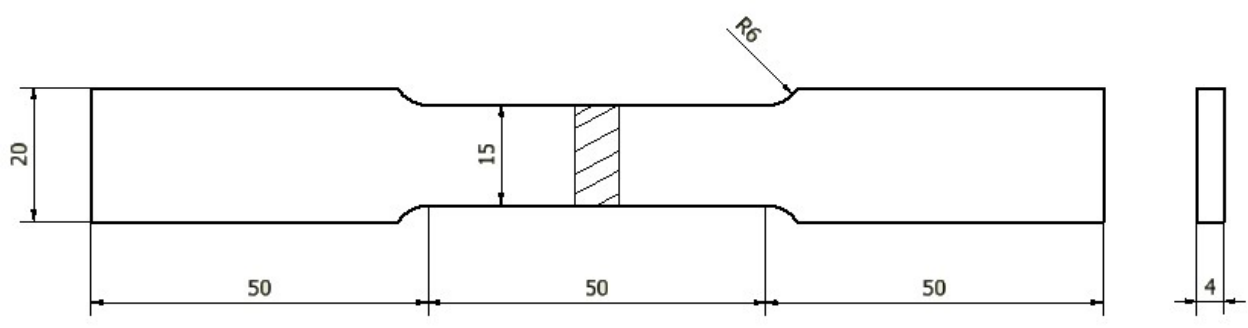

Gambar 6. Spesimen uji tarik

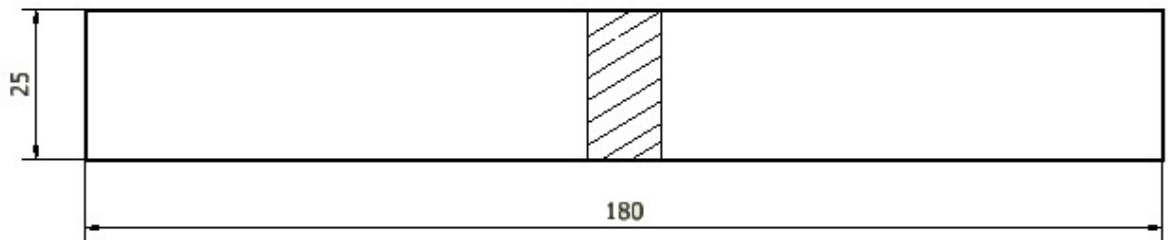

Gambar 7. Spesimen uji kekerasan

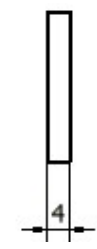

\subsection{Spesimen Pengujian}

Untuk mengetahui sifat mekanis khususnya kekuatan tarik dan kekerasan maka sambungan hasil pengelasan DFSW terlebih dahulu dibentuk spesimen uji tarik dengan ukuran $150 \times 20 \times 4 \mathrm{~mm}$ dan spesimen uji kekerasan dengan ukuran $100 \times 25 \times 6 \mathrm{~mm}$ seperti terlihat pada Gambar 6 dan 7.

Gambar 7 memperlihatkan proses uji kekerasan dan uji tarik sambungan DFSW setelah spesimen dibentuk.
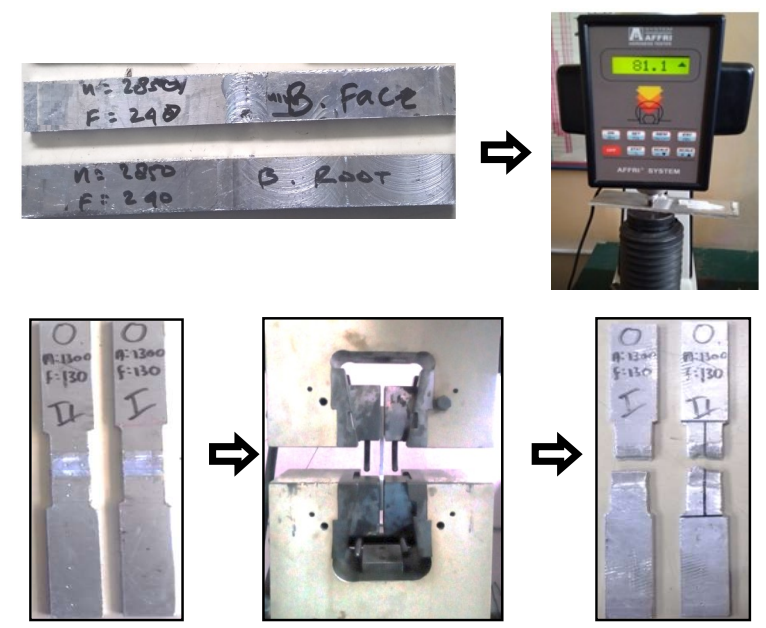

(a

Gambar 7. Pengujian sifat mekanis dengan proses hardness testing (a) dan proses tensile testing (b)

\section{Hasil dan Pembahasan}

\subsection{Hasil Pengujian Kekerasan}

Adapun distribusi nilai kekerasan hasil pengelasan DFSW aluminium paduan AA5052 dan AA 6061 dengan menggunakan tool silinder dalam bentuk grafik ditunjukkan gambar-gambar di bawah ini.

Pada Gambar 8 ditunjukkan distribusi kekerasan Brinell sambungan DFSW pada putaran tool $1300 \mathrm{rpm}$ dengan variasi feeding $43 \mathrm{~mm} / \mathrm{min}, 130 \mathrm{~mm} / \mathrm{min}$ dan $240 \mathrm{~mm} / \mathrm{min}$. Dimana daerah dengan titik kekerasan -1 s.d -6 merupakan distribusi kekerasan brinnel pada Base Material (BM) AA 5052, daerah dengan titik kekerasan 1 s.d 6 merupakan distribusi kekerasan
Brinell pada BM AA 6061 sedangkan titik nol merupakan daerah Welding Nugget Zone (WNZ).

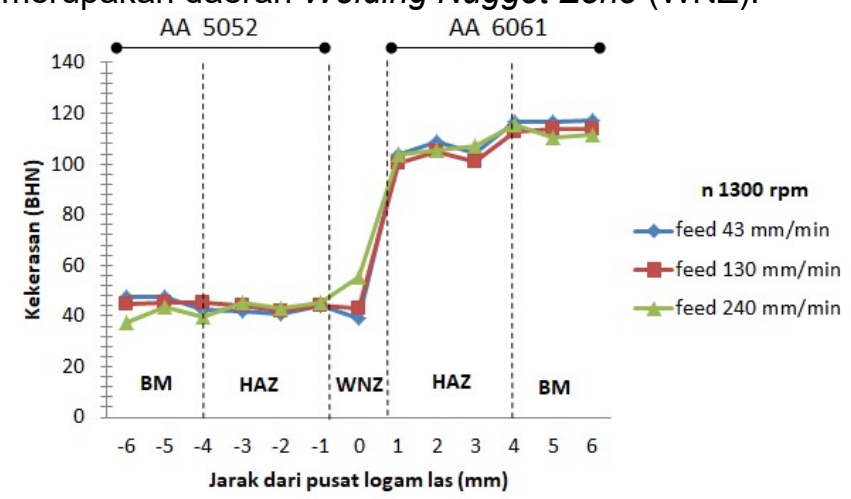

Gambar 8. Grafik distribusi nilai kekerasan sambungan DFSW putaran tool $1300 \mathrm{rpm}$

Pada daerah WNZ umumnya memiliki nilai kekerasan lebih kecil dari daerah Heat Affected Zone (HAZ) dan daerah BM AA 6061. Adapun nilai kekerasan daerah WNZ pada feeding $43 \mathrm{~mm} / \mathrm{min}, 130$ $\mathrm{mm} / \mathrm{min}$ dan $240 \mathrm{~mm} / \mathrm{min}$ tidak jauh berbeda secara berturut-turut sebesar $39 \mathrm{BHN}, 42.8 \mathrm{BHN}$ dan 55.3 BHN.

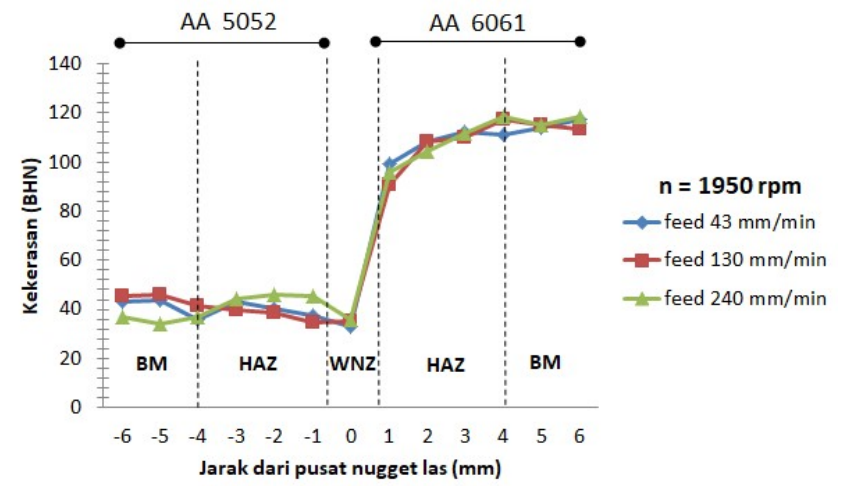

Gambar 9. Grafik distribusi nilai kekerasan sambungan DFSW putaran tool $1950 \mathrm{rpm}$ 
Pada Gambar 9 diatas kekerasan pada putaran tool $1950 \mathrm{rpm}$ juga menunjukkan trend distribusi kekerasan Brinell pada sambungan DFSW sama dengan putaran tool $1300 \mathrm{rpm}$. Distribusi kekerasan logam dasar AA 5052 pada daerah BM, HAZ dan WNS cenderung terdistribusi merata. Demikian pula pada daerah logam dasar AA 6061 juga memiliki kecenderungan kekerasan terdistribusi merata mekipun kekerasannya lebih tinggi dibandingkan daerah WNZ dan logam dasar AA 5052. Nilai kekerasan pada tiga variasi feeding $43 \mathrm{~mm} / \mathrm{min}, 130 \mathrm{~mm} / \mathrm{min}$ dan $240 \mathrm{~mm} / \mathrm{min}$ secara berturut-turut sebesar $32.9 \mathrm{BHN}, 35.1 \mathrm{BHN}$ dan $35.8 \mathrm{BHN}$.

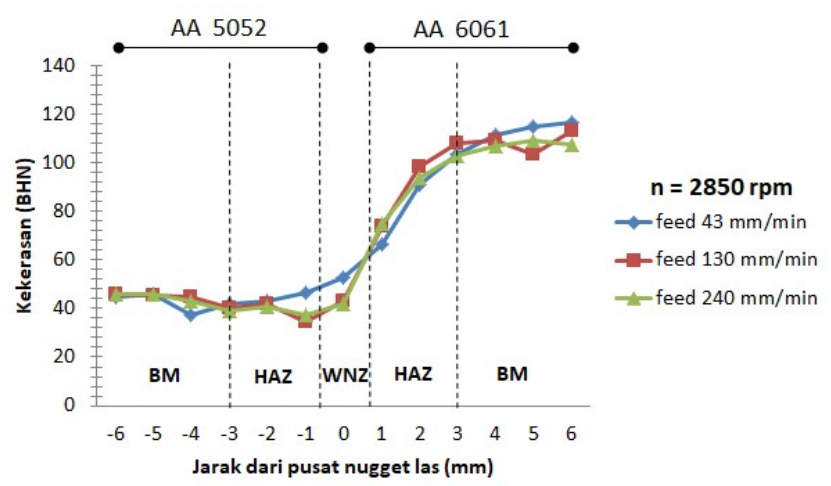

Gambar 10. Grafik distribusi nilai kekerasan sambungan DFSW putaran tool $2850 \mathrm{rpm}$

Demikian pula pada Gambar 10 juga untuk putaran tool $2850 \mathrm{rpm}$ juga memilik trend distribusi kekerasan Brinell yang mirip dengan putaran tool 1300 dan $1950 \mathrm{rpm}$. Distribusi kekerasan pada base material aluminium paduan AA 5052 dan AA 6061 untuk semua daerah BM, HAZ dan WNS cenderung terdistribusi merata. Nilai kekerasan pada BM AA 6061 lebih tinggi daripada daerah WNZ dan material BM AA 5052. Sedangkan kekerasan untuk variasi feeding 43 $\mathrm{mm} / \mathrm{min}, 130 \mathrm{~mm} / \mathrm{min}$ dan $240 \mathrm{~mm} / \mathrm{min}$ secara berturut-turut sebesar 53 BHN, 43.3 BHN dan 41.7 BHN.

Hasil kekerasan bahan yang diperoleh dalam penelitian telah sejalan dengan hasil penelitian yang dilakukan oleh Balamurugan dan Subbaiah [11]. Mereka mempelajari pengaruh bentuk Tool pin dalam proses DFSW antara AA 5052-H32 dan AA 6061-T6.

\subsection{Hasil Pengujian Tarik}

Adapun distribusi nilai kekerasan hasil pengelasan DFSW aluminium paduan AA5052 dan AA 6061 dapat dilihat dalam Gambar 11. Berikut ini menunjukkan kekuatan tarik yang diperoleh dari sambungan DFSW. Dari hasil uji tarik fakta menunjukkan bahwa semua patahan terjadi di sisi BM AA 5052 pada daerah HAZ dan WNZ dimana pada daerah tersebut pada umumnya memiliki nilai kekerasannya terendah. Patahan yang terjadi umumnya patahan getas.

Kekuatan tarik logam dasar aluminium paduan AA 5052 sebesar $172.9 \mathrm{MPa}$ dan aluminium paduan $\mathrm{AA}$ 6061 sebesar $301,68 \mathrm{MPa}$. Semua kekuatan tarik maksimum sambungan pengelasan DFSW lebih rendah dari kekuatan tarik logam dasar AA 6061.

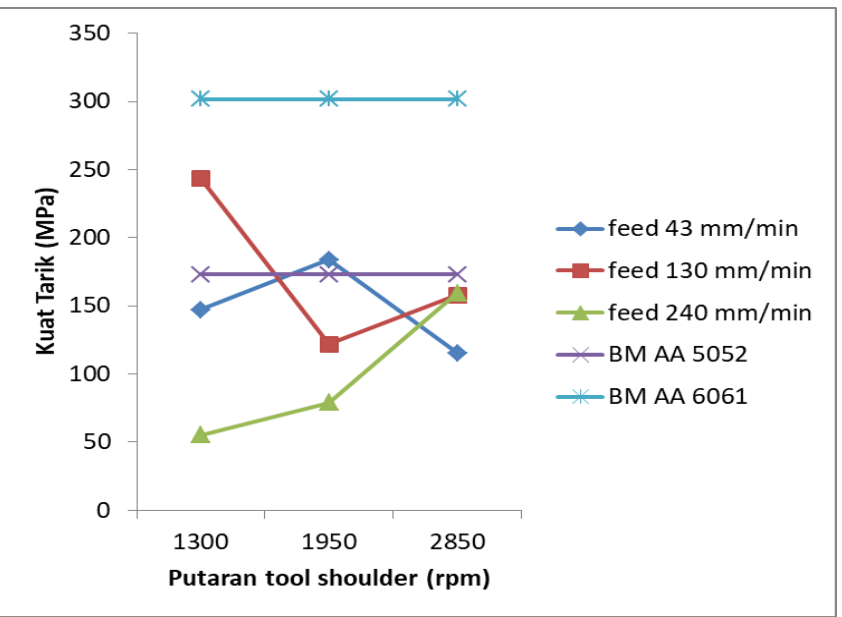

Gambar 11. Grafik kekuatan tarik hasil pengelasan DFSW dengan pin tool silinder

Kekuatan tarik terbesar diperoleh pada putaran tool $1300 \mathrm{rpm}$ dengan feeding $130 \mathrm{~mm} / \mathrm{min}$ sebesar 243.7 MPa. Sambungan pengelasan DFSW pada putaran tool $1300 \mathrm{rpm}$ (feeding $130 \mathrm{~mm} / \mathrm{min}$ ) dan 1950 rpm (feeding $43 \mathrm{~mm} / \mathrm{min}$ ) memiliki kekuatan tarik lebih tinggi dari kekuatan tarik logam dasar AA 5052.

Hasil ini juga telah dikonfirmasi oleh Balamurugan dan Subbaiah yang menyimpulkan bahwa kekuatan tarik pada sambungan lebih rendah dibandingkan dengan base metal [11].

\section{Simpulan}

Hasil kaji eksperimental sifat mekanik sambungan las Dissimilar Friction Stir Welding (DFSW) aluminium paduan AA 5052 dan AA 6061 ini disimpulkan bahwa:

1. Hasil sambungan pengelasan DFSW aluminum paduan AA 5052 dan AA 6061 umumnya dapat tersambung dengan baik meskipun terdapat beberapa cacat.

2. Nilai kekerasan daerah nugget umumnya lebih rendah dari nilai kekerasan dari logam dasar (base metal) dengan nilai kekerasan nugget paling tinggi sebesar 55,3 HBN

3. Hasil uji tarik memperlihatkan bahwa patahan banyak terjadi pada daerah HAZ logam dasar AA 5052 dan daerah nugget karena pada daerah tersebut banyak terjadi cacat dan tingkat kekerasannya lebih rendah dari daerah lainya.

4. Kekuatan tarik sambungan las DFSW aluminium AA 5052 dan AA 6061 yang tertinggi yang diperoleh sebesar $243.7 \mathrm{MPa}$.

\section{Ucapan Terima Kasih}

Pada kesempatan ini penulis dengan tulus mengucapkan terima kasih kepada: 1). Kementrian Penddikan dan Kebudayaan atas dana DIPA yang telah diberikan melalui program penelitian dan pengabdian masyarakat Politeknik Negeri Ujung Pandang tahun 2020. 2). Direktur dan Ketua UPPM Politeknik Negeri Ujung Pandang yang memberikan kesempatan untuk mengikuti program Penelitian Dasar Unggulan Perguruan Tinggi ini. 3) Semua pihak yang terlibat dalam penelitian ini. 


\section{Daftar Pustaka}

[1] Peng G, Yan Q, Hu J, Chen P, Chen Z, Zhang T 2019 Effect of forced air cooling on the microstructures, Tensile strength, and Hardness distribution of dissimilar friction stir welded AA5A06-AA6061 Joints Metals (Basel). 9(3)

[2] Biradar NS, Raman R 2012 Investigation of hot cracking behavior in transverse mechanically arc oscillated autogenous AA2014 T6 TIG welds Metall Mater Trans A Phys Metall Mater Sci. 43(9)3179-91

[3] Leon JS, Jayakumar V 2015 Investigation of Mechanical Properties of Aluminium 6061 Alloy Friction Stir Welding Int J Students' Res Technol Manag. 2(4)140-4

[4] Howeyze M, Arabi H, Eivani AR, Jafarian HR 2018 Strengthening of AA5052 aluminum alloy by equal channel angular pressing followed by softening at room temperature Mater Sci Eng A. $720160-8$

[5] Malopheyev S, Vysotskiy I, Kulitskiy V, Mironov S, Kaibyshev R 2016 Optimization of processing microstructure properties relationship in friction-stir welded 6061-T6 aluminum alloy Mater Sci Eng A. 662136-43

[6] Nandan R, DebRoy T, Bhadeshia HKDH 2008 Recent advances in friction-stir welding Process, weldment structure and properties Prog Mater Sci. 53(6)980-1023

[7] Hasan MM, Ishak M, Rejab MRM 2018 Effect of pin tool flute radius on the material flow and tensile properties of dissimilar friction stir welded aluminum alloys Int $J$ Adv Manuf Technol. 98(9-12)2747-58

[8] Nur R, Sultan AZ, Suyuti MA 2017 Mechanical properties on friction stir welding of aluminum alloy 5052 ARPN J Eng Appl Sci.

[9] Mishra RS, Ma ZY 2005 Friction stir welding and processing Mater Sci Eng $R$ Reports. 50(1-2)1-78

[10] Iswar M, Suyuti MA, Nur R 2019 Optimizing the machining conditions on friction stir welding of aluminum alloy through design experiments InAIP Conference Proceedings.

[11] Balamurugan S, Subbaiah K 2019 Tool Pin Profile Studies on Friction Stir Welded Joints of AA5052-H32 and AA6061-T6 Aluminum Alloys InAdvances in Manufacturing Processes. Springer; p. 663-70

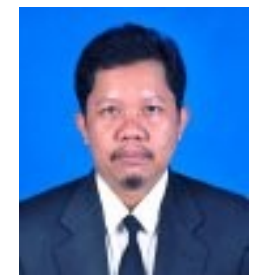

Muhammad Arsyad Suyuti menyelesaikan pendidikan D3 Teknik Mesin spesialis produksi di Politeknik Universitas Hasanuddin pada tahun 1995. Pada tahun 1999 menyelesaiakan pendidikan sarjana teknik S1 di Universitas Hasanuddin. Dan pada tahun 1999-2001 melalui program beasiswa pemerintah kembali belajar dibidang ilmu sains terapan pada program studi D4

Teknologi Rekayasa Manufaktur di Politeknik Manufaktur Bandung (POLMAN Bandung). Pada tahun 2008 menyelesaikan pendidikan magister di Universitas Hasanuddin, Makassar dibidang teknik industri. Saat ini ia bekerja sebagai dosen program studi D4 Teknik Manufaktur di Jurusan Teknik Mesin Politeknik Negeri Ujung Pandang (PNUP) Makassar. Bidang penelitian utama yang digeluti adalah materials \& design, manufacturing technology dan Design \& Modeling Engineering.

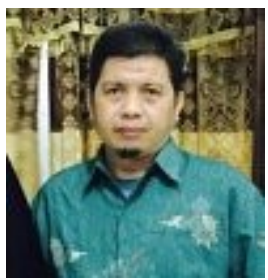

Apollo menyelesaikan pendidikan Diploma Tiga pada Jurusan Teknik Energi Politeknik Universitas Hasanuddin pada tahun 1991 kemudian pada tahun 1996 mendapat beasiswa untuk melanjutkan pendidikan Sarjana di Jurusan Teknik Mesin Institut Teknologi Bandung (ITB) yang diselesaikan pada tahun 1999

Pendidikan Magister Teknik Mesin predikat Cum Laude diselesaikan di Universitas Gadjah Mada (UGM) pada tahun 2011 dengan area riset recovery tembaga larut pada limbah cair pemurnian emas.

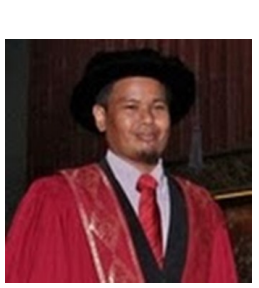

Rusdi Nur menyelesaikan pendidikan D3 Teknik Mesin Politeknik Universitas Hasanuddin pada tahun 1995, kemudian menyelesaikan S1 Teknik Mesin di Universitas Hasanuddin pada tahun 1999. Oleh karena ada program pemerintah pengangkatan Dosen Politeknik, maka mengambil program D4 Teknik Manufaktur Politeknik Manufaktur Bandung selama dua tahun (1999-2001).

Pendidikan magister Teknik Mesin diselesaikan di Universitas Hasanuddin pada tahun 2008 dengan area riset tentang proses produksi. Pada tahun 2016 ia menyelesaikan pendidikan doktoral (Ph.D) bidang Teknik manufaktur di Universiti Teknologi Malaysia, Johor Malaysia. Saat ini ia bekerja sebagai dosen di Jurusan Teknik Mesin Politeknik Negeri Ujung Pandang. Bidang penelitian utama yang digeluti adalah sustainable manufacturing, forming process, welding process, and machining process. 